\title{
Crustal and Upper Mantle Structure of the French Massif Central Plume
}

\author{
Barth $\mathrm{A}^{1}$, Jordan $\mathrm{M}^{2}$, Ritter JRR ${ }^{1}$ \\ ${ }^{1}$ Geophysical Institute, University of Karlsruhe, Hertzstr. 16, 76187 \\ Karlsruhe, Germany \\ ${ }^{2}$ Department of Geology and Geophysics, University of Utah, 135 South \\ 1460 East, Salt Lake City, Utah 84112, USA
}

\begin{abstract}
The Cenozoic volcanism in the French Massif Central region is fed by an upper mantle plume, which was revealed by teleseismic tomography about 10 years ago. This contribution reviews earlier studies and applies a new method to image the crust and upper mantle in the region. Since teleseismic tomography alone has only moderate ability to resolve crustal structures, we perform an integrated study by a joint teleseismic-gravimetric inversion to investigate the gross crustal imprints of the Massif Central. We use a 3-dimensional joint inversion code, which allows a variable model parameterisation, and $3 \mathrm{D}$ ray tracing to perform an iterative inversion. Travel time residuals are corrected for Moho topography and sedimentary influences to avoid mapping of known crustal structure into the mantle.

Our study finds a prominent low-velocity structure in the upper mantle, which is interpreted as the thermal signature of the Massif Central plume. With a modelled diameter of about $100-120 \mathrm{~km}$ it reaches down to at least $330 \mathrm{~km}$ depth. The average determined seismic $P$-wave velocity contrast is $-0.6 \%$ to $-1.0 \%$ in the shallow asthenospheric mantle and deeper upper mantle. We found two low-velocity channels in the crustal layer beneath the Cantal/Monte Dore and south of the Devès volcanic fields. A zone of mainly high density and increased seismic velocity is determined in the crust south of the Limagne Graben between the two volcanic fields. Furthermore the Massif Central is characterised by increased seismic scattering in the lithosphere as found by studying the teleseismic $P$-wave coda. We interpret the detected high-velocity/high-density body and the lithospheric scatterers as cooled magmatic intrusions, produced during the $\mathrm{Ce}$ nozoic volcanism.
\end{abstract}




\section{Introduction}

Geophysical and geochemical research has been performed in the French Massif Central (Fig. 1) to study the structure and geodynamic implications of the underlying mantle plume. This contribution combines seismological and gravimetric observations for a joint inversion to image the crustal and upper mantle structures and to interpret their geodynamical implications.

The French Massif Central is part of the European Variscan mountain belt (Matte 1986). In the Paleocene (65-35 Ma) a first volcanic stage took place, followed by a phase of rifting as part of the European Cenozoic Rift

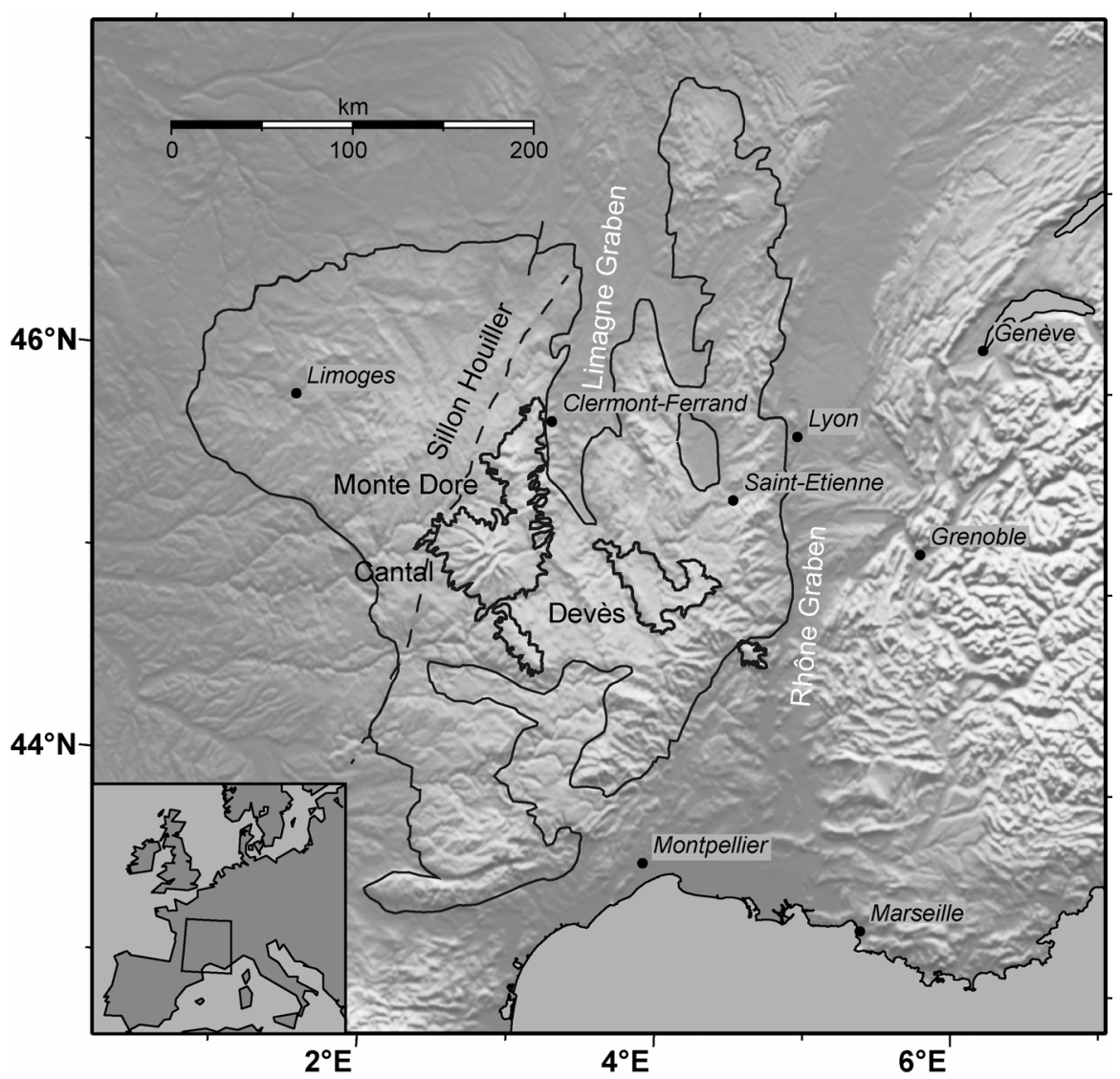

Fig. 1. The French Massif Central region. The thick outlines indicate Neogene volcanic areas, the thinner line represents the Variscan basement of the Massif Central 
System during the Oligocene (26-24 Ma). In the Massif Central the main rift is the Limagne Graben in its northern part. A second volcanic stage began in the early Miocene (20 Ma) with latest activity about $6 \mathrm{ka} \mathrm{BC}$ (Brousse et al. 1969, Miallier et al. 2004).

To study the origin of the volcanism and the deep structure of the Massif Central a teleseismic tomography project was conducted in 1991/92 by running a temporary station network (Fig. 2) in the central Massif Central region (Granet et al. 1995a). The teleseismic $P$-wave tomography revealed a low-velocity zone in the upper mantle beneath the Massif Central down to at least $180 \mathrm{~km}$ depth, which was interpreted as a small mantle plume. Later studies estimated its depth to at least $250-270 \mathrm{~km}$ (Granet et al. 1995b, Piromallo and Morelli 2003), with a seismic $P$-wave velocity contrast of $-2 \%$ to $-2.5 \%$ at $100-270 \mathrm{~km}$ depth. In the lithosphere two vertical low-velocity channels were detected which coincide with the location of the volcanic complexes of Cantal/Mont Dore and Devès (Granet et al. 1995a). Taking into account the prominent Bouguer gravity low in Massif Central region, it was concluded that no or only a small amount of melt is needed to explain the negative seismic velocity anomaly in the mantle (Granet et al. 1995a).

Sobolev et al. (1997b) showed that the detected velocity perturbation could be explained nearly entirely by temperature. In their model the excess temperature of the plume is $150-200^{\circ} \mathrm{C}$ relative to the average potential temperature of the upper mantle. Their temperature model was used as an input for a dynamic convection model. The resulting topography and geoid agreed well with observations in the region of interest (Sobolev et al. 1997a). Ritter (2005) estimated the buoyancy flux of the plume using the above excess temperature, a plume radius of $60-75 \mathrm{~km}$, non-linear viscosity and a Poiseulle flow law. This calculation resulted in a buoyancy flux of $0.09-0.7 \mathrm{Mg} / \mathrm{s}$, what is about ten times more than the flux of the Eifel plume under the Rhenish Massif (Ritter 2005).

According to Werling and Altherr (1997) the petrologic analysis of equilibrated xenoliths gives a steady-state geotherme of about $90 \mathrm{mWm}^{-2}$. They found a thinned lithosphere of about 70-80 km thickness beneath the Massif Central. Dèzes et al. (2004) assume that thermal thinning of the lithosphere occured since the middle Miocene (14 Ma), when increased volcanic activity took place in the southern Massif Central. After Sobolev et al. (1997b) the main lithospheric thinning occurs beneath the volcanic fields in NW-SE direction, which was determined by Müller et al. (1997) as the orientation of maximum horizontal compressional stress. Using this stress-field deduced from earthquake focal mechanisms, geological indica- 
tors, borehole breakouts, overcoring and hydraulic fracturing data, they argued that first-order stress orientations would be the same in the crust and the subcrustal lithosphere beneath the Massif Central.

Recent mantle xenolith studies found geochemical differences in samples from the northern Massif Central, dominated by the Limagne-Graben structure, and the southern part with the large Cantal volcanic area (Fig. 1): Lenoir et al. (2000) analysed trace elements of peridotites and found older and more refracted samples in the region north of $45.5^{\circ} \mathrm{N}$ than in the area south of it. Downes et al. (2003) combined these results with isotopic data

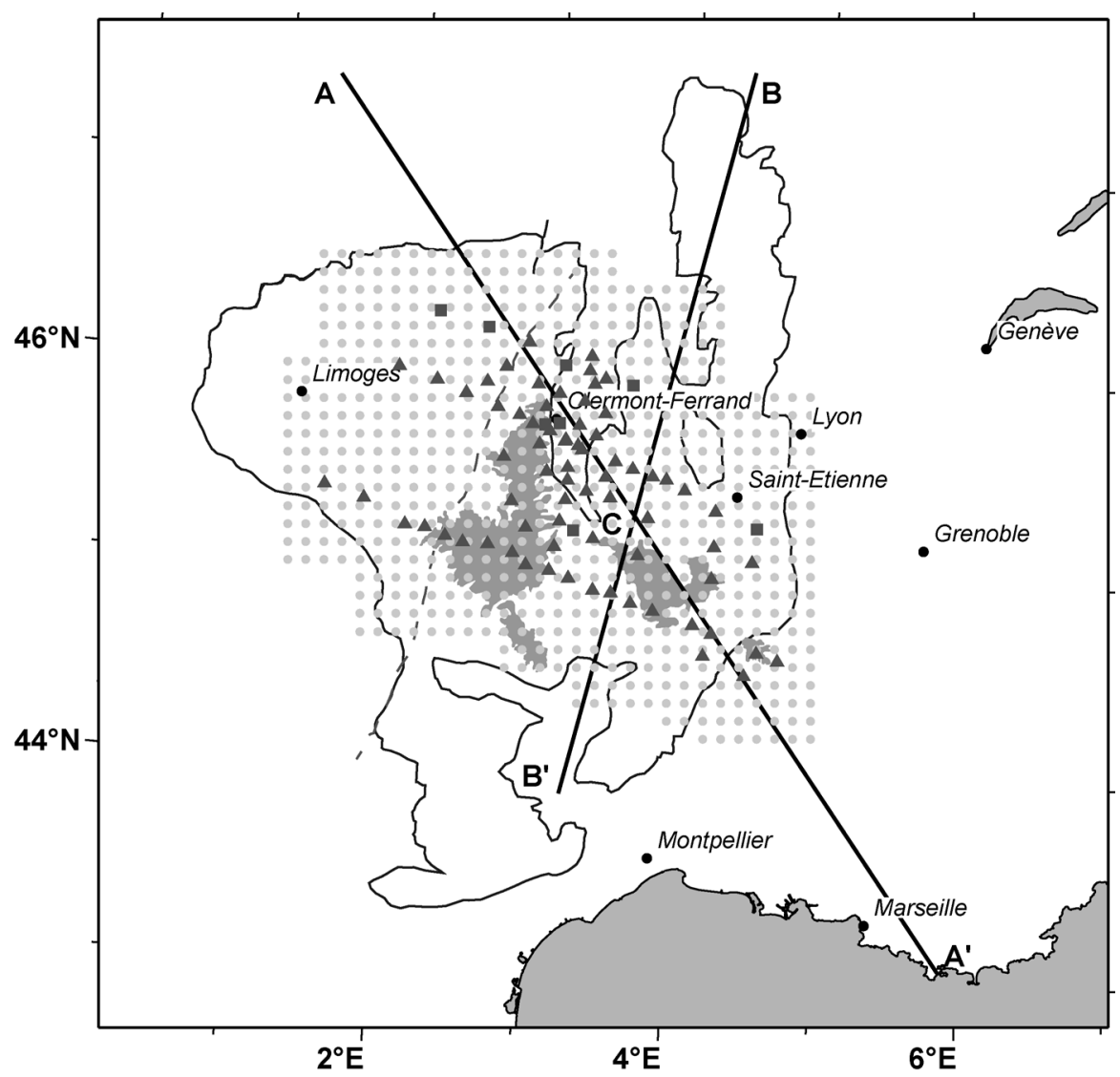

Fig. 2. Location map of seismic station distribution, showing the mobile Massif Central network (triangles, Granet et al. 1995a) and permanent stations (squares). The two lines indicate the positions of the cross-sections in Fig. 11, 12. The grey dots indicate the resampled linear grid of the Bouguer data. Grey-shaded regions indicate Neogene volcanic areas 
and confirmed the differences between the two regimes. Lenoir et al (2000) assigned the consolidation of the two different lithospheric domains to the Variscan orogeny and suggested an asthenospheric channelling effect along the two lithospheric blocks. Thus upwelling asthenosphere in the South follows the lithospheric suture zone, which acts as a mechanical boundary.

Granet et al. (1998), however, identified two other regions by a seismic shear-wave splitting study. They distinguish the region east of the Sillon Houiller fault zone and the region west of it by different anisotropic patterns. In the East they determined the fast polarisation direction $\varphi$ of the shear-waves to be roughly parallel $\left(\varphi \approx \mathrm{N} 100^{\circ} \mathrm{E}\right)$ to the lithospheric lowvelocity zone found by Granet et al. (1995b) and related this polarisation direction to magmatic flow during periods of volcanic activity. In the West they detected $\varphi$ parallel to the Sillon Houiller $\left(\varphi \approx \mathrm{N} 30^{\circ} \mathrm{E}\right)$. This division was explained by a stable lithospheric regime in the West and a heterogeneous, reworked lithosphere beneath the Neogene volcanic areas in the East.

To study the lithosphere-asthenosphere system of the Massif Central we derive a detailed tomographic model. We use a new imaging technique with the same teleseismic recordings used by Granet et al. (1995a,b) and additional crustal travel time corrections (Barth 2002) as well as gravity data. We review analyses of coda phases, which estimate the distribution of small-scale structures in the lithosphere that cannot be resolved by teleseismic tomography. The integrated structural model is then interpreted together with recent geophysical and geochemical models.

\section{Joint inversion of travel time residuals and gravity data}

Based on the teleseismic waveforms recorded by the mobile stations of the Massif Central project 1991/92 (Granet et al. 1995a) and additional permanent stations plus a Bouguer gravity dataset (Fig. 2), a new inversion model is obtained using the JI-3D method (Jordan 2003). Compared to previously published models our joint inversion uses gravity and travel time data, a variable model parameterisation, individual a priori station corrections for crustal structure, 3D ray tracing, an iterative quasi nonlinear approach and 3D resolution tests. This approach gains a deeper and better resolved model than previously available. 


\subsection{Inversion routine and starting model}

JI-3D (Joint Inversion in 3 Dimensions) is an inversion method that simultaneously determines 3D density and seismic velocity perturbations from Bouguer gravity and seismic travel time delays. The model parameterisation consisting of blocks and nodes is adapted to the observed seismic ray distribution. The blocks explicitly define the volume that contributes to the determination of an individual model parameter (Fig. 3). Since the ray density is often highest below the centre of the station network and back azimuths are best distributed there, model blocks there have a smaller size

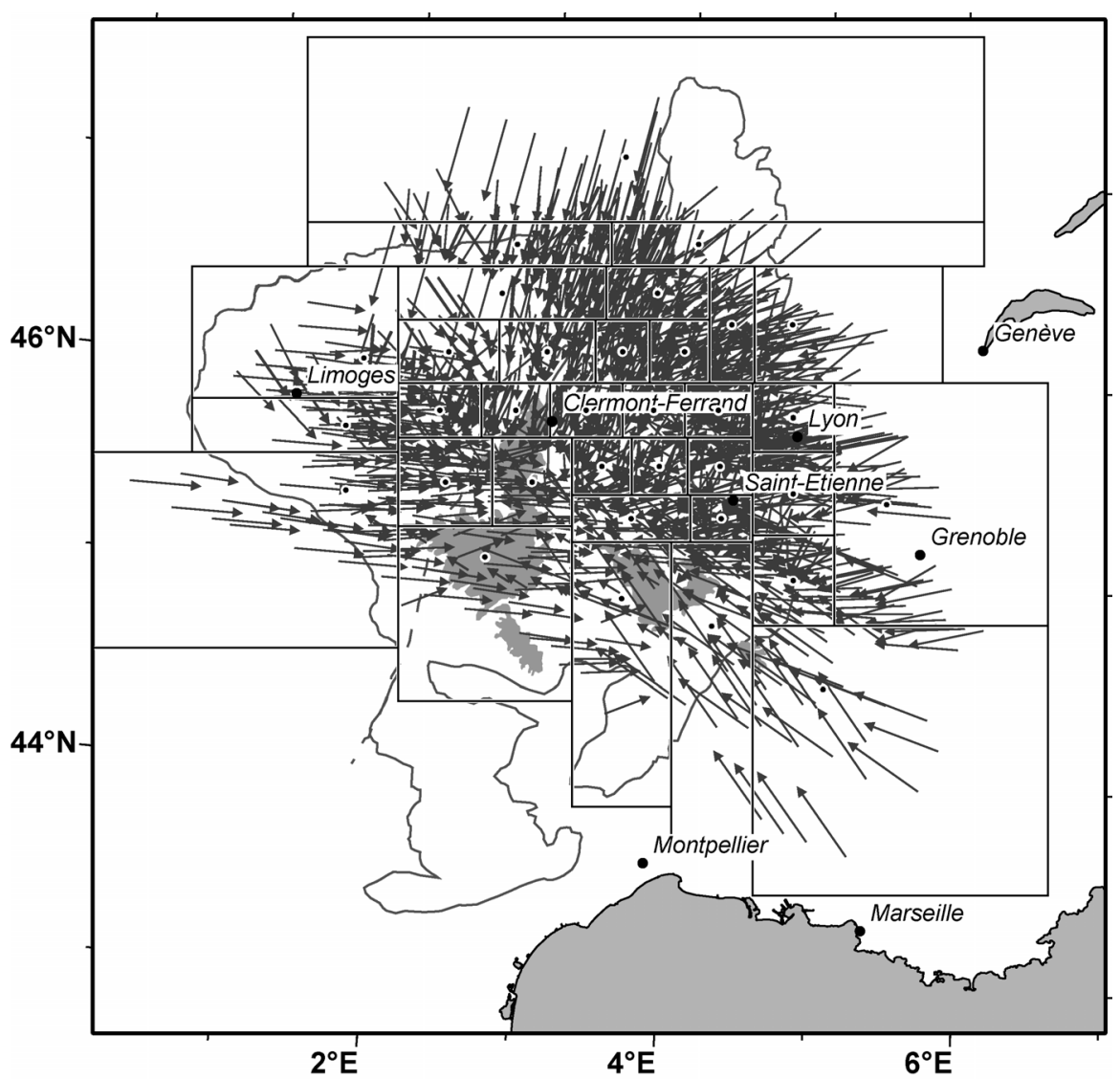

Fig. 3. Parameterisation and ray distribution of model layer five $(178 \mathrm{~km}$ to $252 \mathrm{~km}$ depth). Arrows are projections of incoming teleseismic rays within the layer. Dots indicate the nodes of the surrounding blocks and correspond to the spatial centre of data information density 
than model blocks at the edges. The parameterisation is designed so that all model parameters are equally well resolved, which leads to stable and more unique results without oscillations and only minimum vertical smearing. The actual velocity parameter is assigned to a node at the centre of information of each model block, where ray density is highest. This allows exact control over the resolution properties and avoids artificial velocity jumps at the block boundaries. 3D ray tracing is performed iteratively through the updated velocity model and is based on Steck and Prothero (1991). Using the Bayes algorithm after Zeyen and Achauer (1997), JI-3D minimises iteratively the following four quantities and conditions (see Eq. 1):

1. the difference $\Delta \vec{d}$ between the observed data vector and the synthetic data vector predicted by the current inversion model (including travel time residuals and Bouguer anomalies),

2 . the difference between the velocity model parameters $\Delta \vec{v}$ and those predicted by the density model parameters $\Delta \rho$ and the correlation between variations of velocity and density parameters in matrix $\boldsymbol{B}$,

3. the difference $\Delta \vec{p}$ between the parameters of the initial model and the current model (including velocity and density perturbations),

4. the difference $\Delta \vec{p}_{\text {dens }}$ between modelled densities in adjacent density blocks weighted with distance $\Delta \boldsymbol{R}$.

While points 1 and 2 represent the physical imaging process, 3 and 4 are used to obtain further numerical stability. Thus the summed object function to be minimised is:

$$
\begin{aligned}
& {\left[\Delta \vec{d}^{T} \boldsymbol{C}_{\boldsymbol{d}}^{-1} \Delta \vec{d}\right]+\left[(\Delta \vec{v}-\boldsymbol{B} \Delta \rho)^{T} \boldsymbol{C}_{\boldsymbol{B}}^{-1}(\Delta \vec{v}-\boldsymbol{B} \Delta \rho)\right]+} \\
& {\left[\vec{p}^{T} \boldsymbol{C}_{\boldsymbol{p}}^{-1} \Delta \vec{p}\right]+\left[\left(\Delta \vec{p}_{\text {dens }} / \Delta \boldsymbol{R}\right)^{T} \boldsymbol{C}_{\boldsymbol{S}}^{-1}\left(\Delta \vec{p}_{\text {dens }} / \Delta \boldsymbol{R}\right)\right] \rightarrow \min }
\end{aligned}
$$

The inversion process depends highly on the a priori variances that are contained in the following covariance matrices (Jordan 2003): The data covariance matrix $\boldsymbol{C}_{\boldsymbol{d}}$, the coupling covariance matrix $\boldsymbol{C}_{\boldsymbol{B}}$, the model covariance matrix $\boldsymbol{C}_{\boldsymbol{p}}$ and the smoothing covariance matrix $\boldsymbol{C}_{\boldsymbol{S}}$. 
$\boldsymbol{C}_{\boldsymbol{d}}$ contains weighted errors for the travel time residuals and gravity data as a priori variances. The different influence of seismic and gravimetric data is considered by an additional constant factor. The a priori variances in matrices $\boldsymbol{C}_{\boldsymbol{p}}, \boldsymbol{C}_{\boldsymbol{B}}$ and $\boldsymbol{C}_{\boldsymbol{S}}$ are determined through a trade-off process to achieve high variance reductions at moderate model lengths.

Due to the unfavourable ray distribution at crustal depths teleseismic inversion tends to map upper mantle heterogeneities into the little constrained crust. Therefore, we choose to include short-wavelength gravity data to improve the near surface resolution of our study. To integrate both data sets we employ an empirical law for the density-velocity relation that was formulated by Birch (1961):

$$
B=d v / d \rho=3 \cdot 10^{-3} \frac{\mathrm{km}}{\mathrm{s}} / \frac{\mathrm{kg}}{\mathrm{m}^{3}} .
$$

A similar relation was also found by Christensen and Mooney (1995). The variance of the coupling $B$ between velocity and density parameters is chosen so that the velocity and density model are effectively coupled without forcing identical anomalies.

Our inversion model consists of seven layers (Table 1). The uppermost layer includes topography and a priori known crustal station effects. The deepest layer has to be considered as possibly contaminated with structure projected from below the model. Therefore we only interpret layers two to six at a maximum depth of $330 \mathrm{~km}$, where vertical smearing effects from adjacent layers are negligible.

Table 1 Structure of the model used for the inversion

\begin{tabular}{lrll}
\hline $\begin{array}{l}\text { Layer } \\
\text { [number] }\end{array}$ & $\begin{array}{l}\text { Depth } \\
{[\mathbf{k m}]}\end{array}$ & $\begin{array}{l}\text { Background velocity } \\
{[\mathbf{k m} / \mathbf{s}]}\end{array}$ & \begin{tabular}{l} 
Inversion mode \\
\hline 1
\end{tabular} \\
2 & $-2-0$ & 5.80 & none, fixed \\
3 & $0-35$ & 6.50 & teleseismic-gravimetric \\
4 & $35-106$ & 8.04 & teleseismic \\
5 & $106-178$ & 8.11 & teleseismic \\
6 & $178-252$ & 8.32 & teleseismic \\
7 & $252-329$ & 8.60 & teleseismic \\
\hline
\end{tabular}



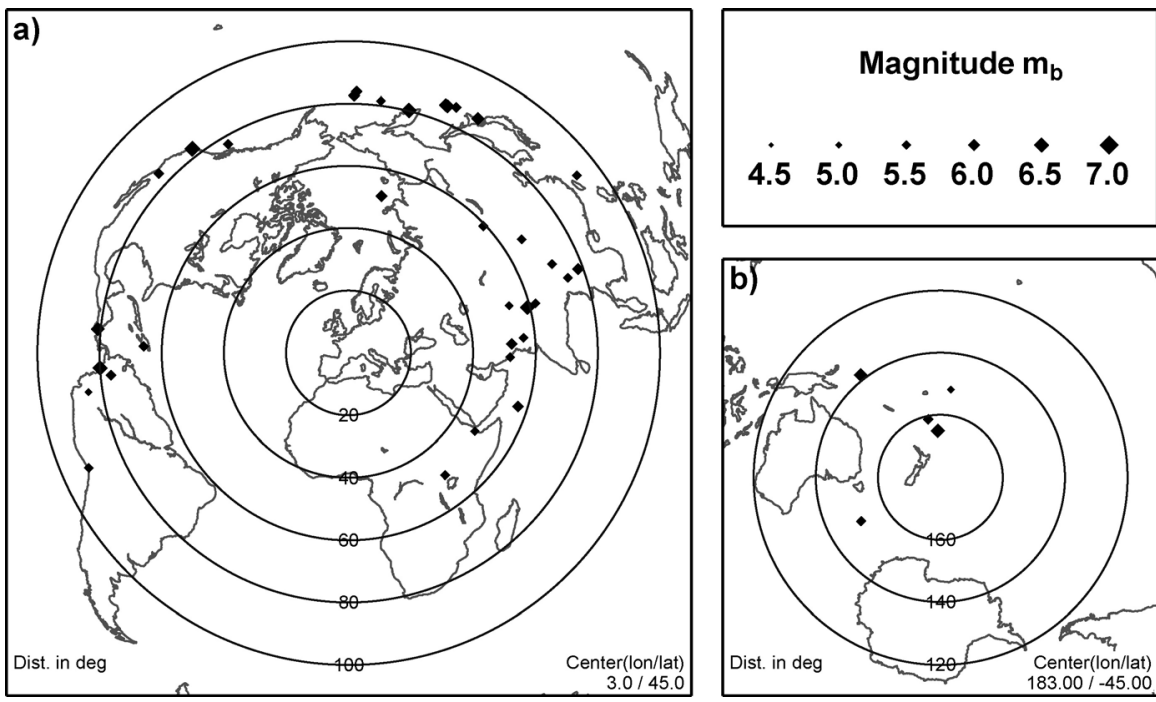

Fig. 4. Event distribution used for the teleseismic tomography. Circles indicate distance in degrees from the centre of the network. a) shows 38 epicentres which provided $P$-phases as first arrivals, b) 6 events with $P K P$-phases. Hypocentre locations were taken from Engdahl et al. (1998)

\subsection{Data selection}

Both datasets, gravity and travel times, are significantly affected by crustal anomalies. Mainly sediments and the Moho topography have a distinct influence on the data (Waldhauser et al. 1998), but are known in the region from numerous previous studies (references in Barth 2002). We use a priori constraints of the crustal structure to avoid artefacts in the otherwise underconstraint crustal layer. To have two consistent datasets for the joint inversion, the data are additionally reduced to sea level: The gravity data are reduced to Bouguer anomalies (excluding topographic effects); the teleseismic travel times are corrected for the travel time of the rays from sea level to actual station elevation. As background velocity model we use iasp91 (Kennett and Engdahl 1991).

\section{Travel times}

We determined 1457 arrival times from 44 earthquakes recorded during the teleseismic field experiment from October 1991 until April 1992 (Granet et al. 1995a) to have a consistent dataset and quantitative error estimates as a priori data variances for the Bayes inversion. The event distri- 
bution is shown in Fig. 4. The azimuthal coverage is good apart from a gap at SSW-backazimuthal direction.

We correct the picked arrival times for known crustal deviations relative to the iasp91 model. These deviations include variations in sediment thickness, station elevation and Moho topography, and are used to determine individual 1D velocity models for each station site. We then correct the respective crustal residuals according to their theoretical angle of ray incidence (Barth 2002, Martin et al. 2005). In general we find negative correction terms in the whole region due to the elevated Moho $(\sim 30 \mathrm{~km}$ depth, Zeyen et al. 1997) relative to the iasp91 Moho ( $35 \mathrm{~km}$ depth). The positive correction terms mainly occur in the Rhône- (Southeast) and the LimagneGraben (North) due to the low-seismic velocity of the sediments. Most correction terms vary between $-0.1 \mathrm{~s}$ and +0.1 , large enough to be important for a seismic inversion (Fig. 5).

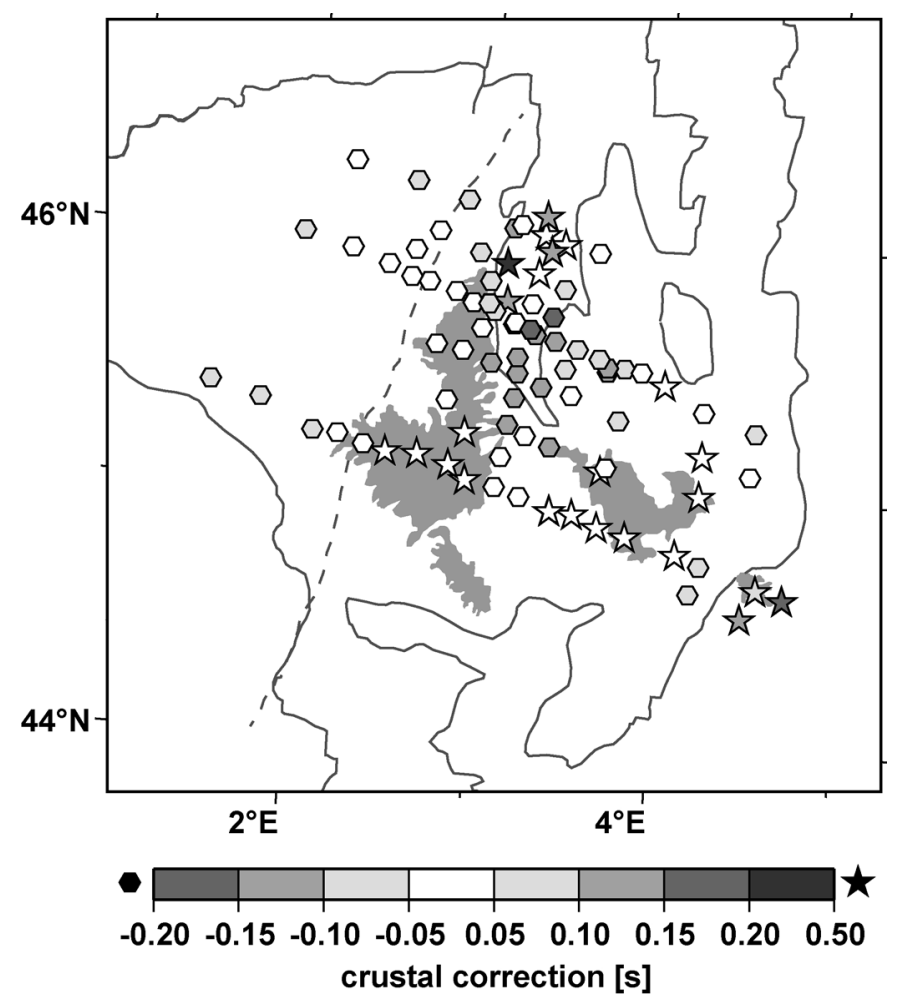

Fig. 5. Crustal corrections for travel times for each seismic station. Stars indicate positive values (later arrival time than iasp91), hexagons indicate negative values (earlier arrival time) 
Following Evans and Achauer (1993) we normalised the corrected residuals by subtracting the average residual of each event separately. The resulting relative residuals (in the following just called residuals) are free of first order effects from outside the model (source uncertainties and source-side heterogeneities). The average residuals for each station (Fig. 6) are negative in the North of the station network. In the South and South-

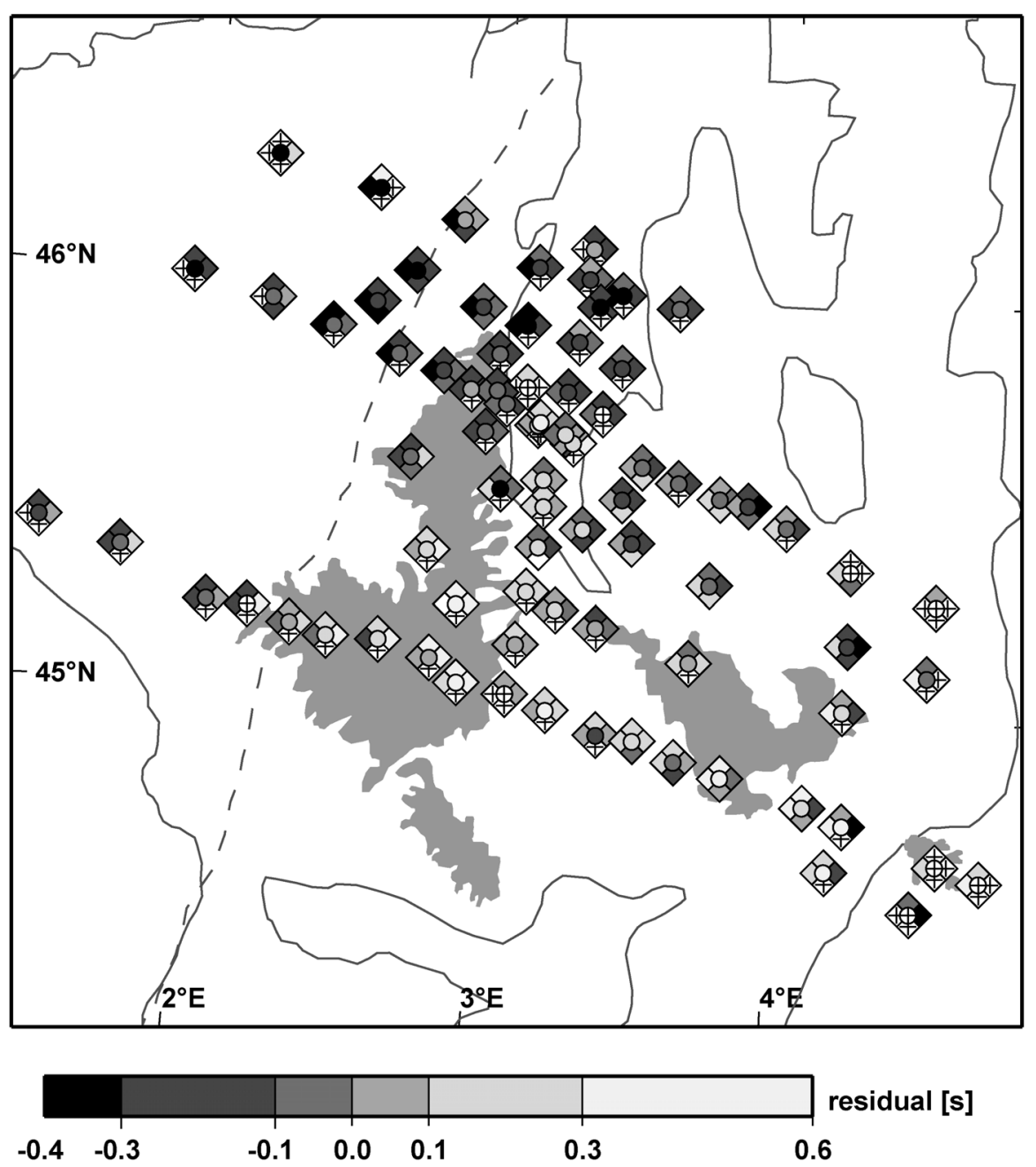

Fig. 6. 5-segment plot of relative residuals for each seismic station. The four outer segments represent the average relative residual for rays with an incidence from N, S, E and W. Accordingly, the central segment represent the relative residuals of vertically incident core phases. A cross marks segments containing no data 
east the average residuals are positive indicating a broad low-velocity anomaly at depth. The maximum residuals are found in the southern part of the Limagne Graben and further south. The maximum contrast between the main anomaly and the residuals in the surrounding region is about $0.4 \mathrm{~s}$ for near-vertical ray incidence. Stations in the East show positive residuals for rays incident from the West, which limits the eastern extension of the plume. Similarly, stations in the West have positive delays for rays from the East (Fig. 6).

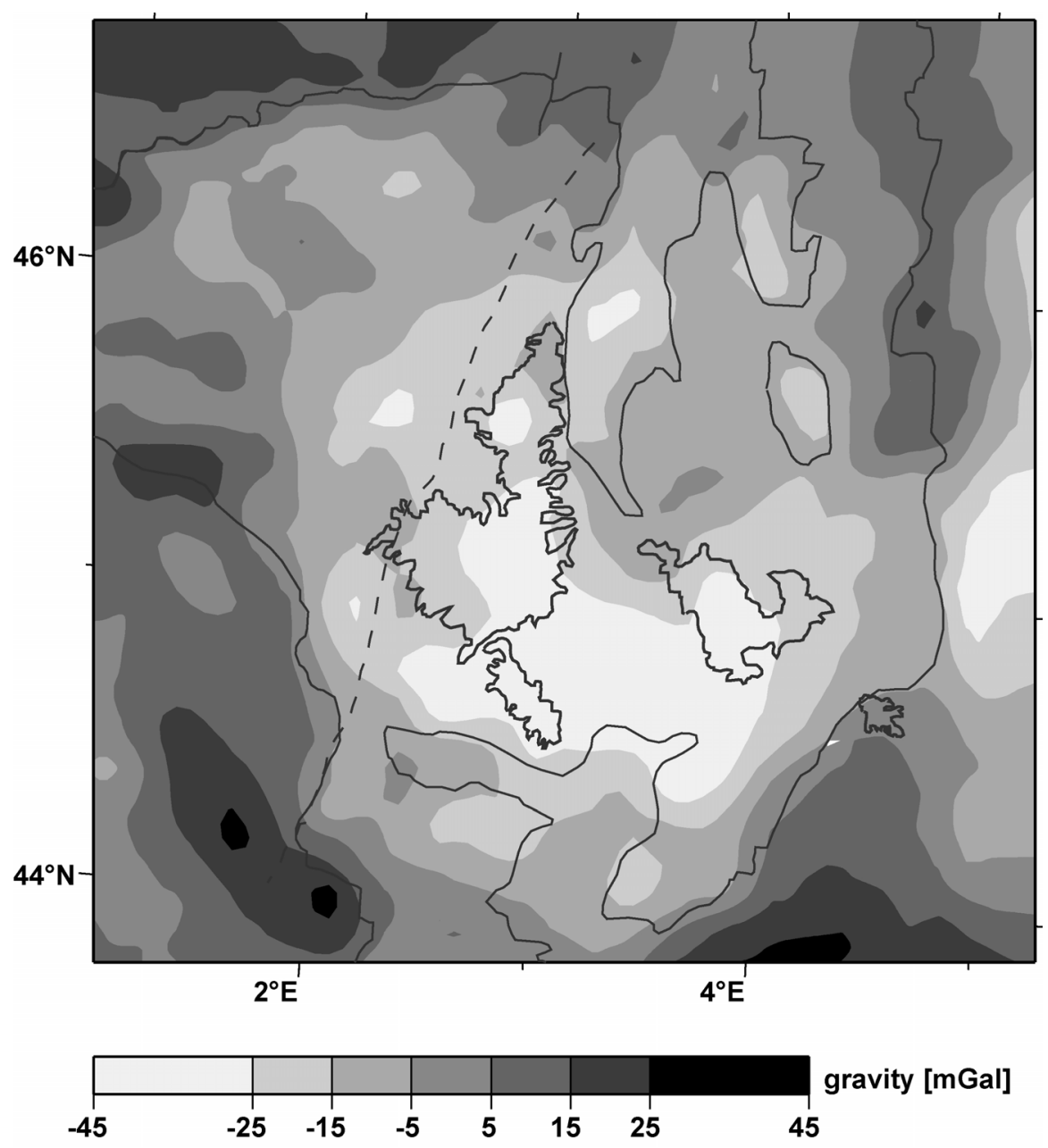

Fig. 7. Interpolated basic input Bouguer gravity data 


\section{Gravity}

Figure 7 shows the basic dataset of Bouguer anomalies interpolated by splining from a regular $5^{\prime} \times 5^{\prime}(\approx 10 \mathrm{~km} \times 10 \mathrm{~km})$ grid. The data was provided by the Bureau de Recherches Géologique et Minière (BRGM, Orléans). The influence of the Alpine orogenic root in the East (negative anomaly starting at $5^{\circ} \mathrm{E}$ and $45^{\circ} \mathrm{N}$ in Fig. 7) and the continental margin in the Southeast (positive anomaly starting at $4^{\circ} \mathrm{E}$ and $44^{\circ} \mathrm{N}$ in Fig. 7) occur at the edges of the area of interest and are excluded from the final dataset
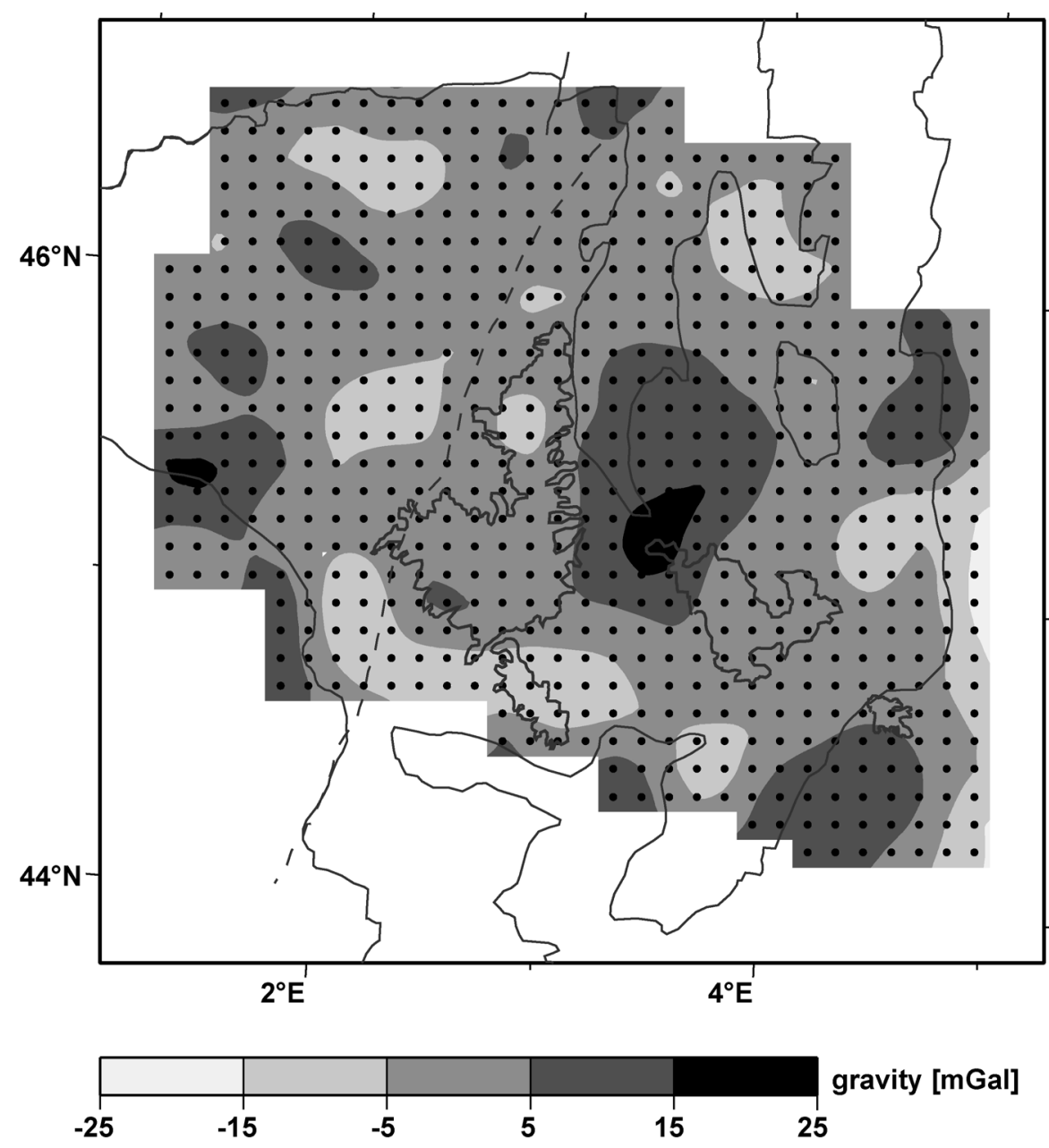

Fig. 8. Gridded gravity data used for the joint inversion. Grid spacing is $10 \mathrm{~km}$ 
(Fig. 8). The dominant signal, in Fig. 7 is a negative Bouguer gravity anomaly in the centre of the study region. It results from the mantle plume below the Massif Central, which is a zone of increased temperature causing reduced density (Sobolev et al. 1997b). This basic dataset is corrected for the crustal influences described above and for the gravity signal of the Alpine orogenic root and the continental margin (Bauer 1995). Since teleseismic resolution is high in the mantle, we include additional gravity constraints only in the crust, where ray incidence is mostly vertical and thus resolution is low. So we perform the joint teleseismic-gravimetric inversion only in the crustal layer, and reduce the corrected Bouguer signal to effects that primarily result from the crustal layer by spatial filtering (Fig. 8).

Density anomalies at a certain depth cause Bouguer anomalies with a minimum horizontal extent of three to four times the depth (in case of a cylindrical body, see Ritter et al., this volume). Accordingly low-pass wavelength filtering is used to remove gravity anomalies from large mantle heterogeneities. To keep the crustal anomalies in our data, we set the wavelength for the maximum gravity signal to $140 \mathrm{~km}$ (four times the crustal layer depth of $35 \mathrm{~km}$, see Table 1). Very small-scale density anomalies cannot be resolved, because the model parameterisation in the crustal layer is too coarse. So a high-pass wavelength filter with a minimum wavelength of $60 \mathrm{~km}$ is used in addition. The remaining crustal gravity signal (resampled to a $10 \mathrm{~km} \times 10 \mathrm{~km}$ grid, Fig. 8) is free of the major negative anomaly of the original input dataset (Fig. 7), which thus is assigned to greater depth. Beside several second-order effects, the resulting dataset shows a positive Bouguer anomaly of about $20 \mathrm{mGal}$ in the central part of the area. As we will discuss in Sect. 4 this anomaly can be assigned to a high-density body, which possibly results from cooled magma intrusions.

\subsection{Modelling results}

After five iterations the joint inversion converges to a $31.8 \%$ variance reduction for the velocity model and $14.3 \%$ for the density model. Further iterations do not improve the variance reduction. According to Jordan (2003), these low-variance reductions are due to the large model block sizes especially at the edges of the deep layers (Fig. 3). Since the inversion results in a homogeneous velocity for each block, heterogeneities inside a block cannot be modelled. Thus, on one hand large block sizes are necessary in deep layers to achieve a uniform resolution and consequently a uni- 
formly constrained model and on the other hand they are the reason for low-variance reductions.

The modelling results after the final iteration are shown as horizontal (Fig. 9 and 10) and vertical cross-sections (A-C-A' and B-C-B' in Fig. 11, for location see Fig. 2) through the model. $P$-wave velocity perturbations are given in percent deviation from the starting model (Table 1). These sections show a continuous low-velocity anomaly (LVA) of about 100$120 \mathrm{~km}$ diameter. In the crustal layer the LVA $(-0.5 \%$ to $-0.7 \%$ velocity contrast with respect to the surrounding) is split in two parts and coincides spatially with the Cantal/Monte Dore and Devès volcanic complexes (Fig. 10a). In the mantle layers the LVA broadens with a partly increased velocity contrast of up to $-0.8 \%$ (Fig. 10b-f). As previous authors we interpret the LVA as a mantle plume. In the northwestern part relatively increased velocities are found in our model. A high-density body (density amplitude $+0.5 \%$ ) is revealed in Fig. 9, resulting from the positive gravity

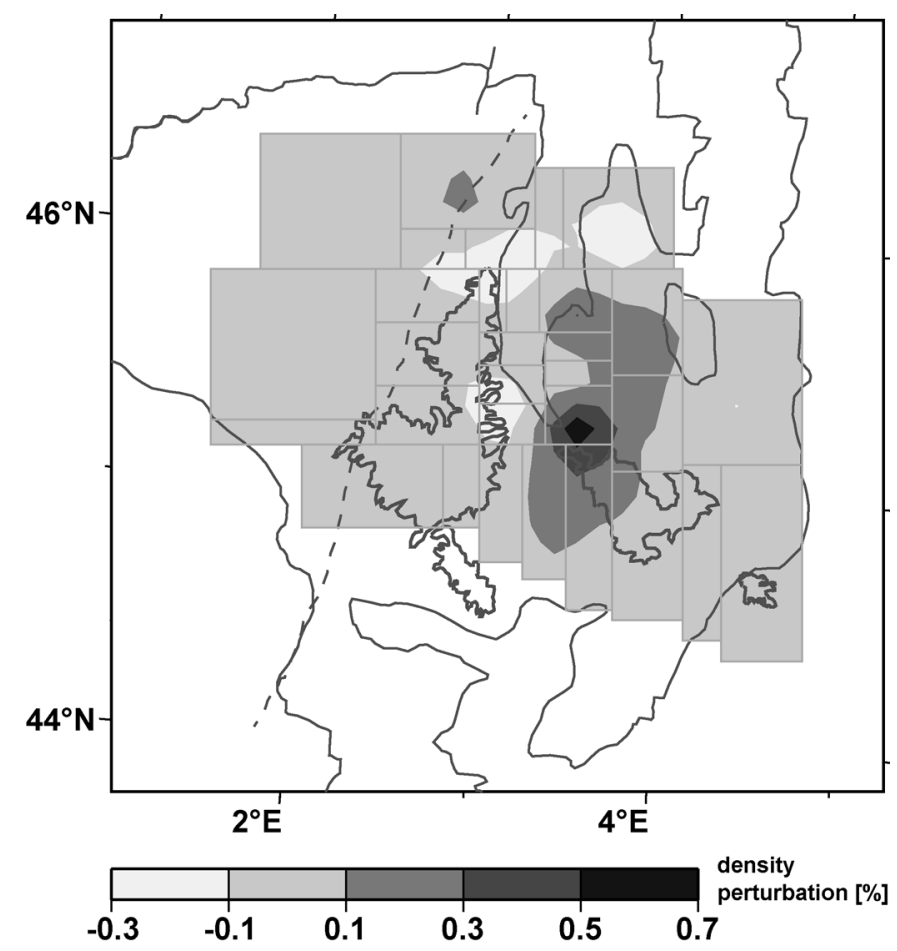

Fig. 9. Horizontal cross-section of the crustal density model at $0 \mathrm{~km}$ to $35 \mathrm{~km}$ depth (layer two of the inversion model). See Fig. 10 for the velocity model 
174 Barth A, Jordan M, Ritter JRR
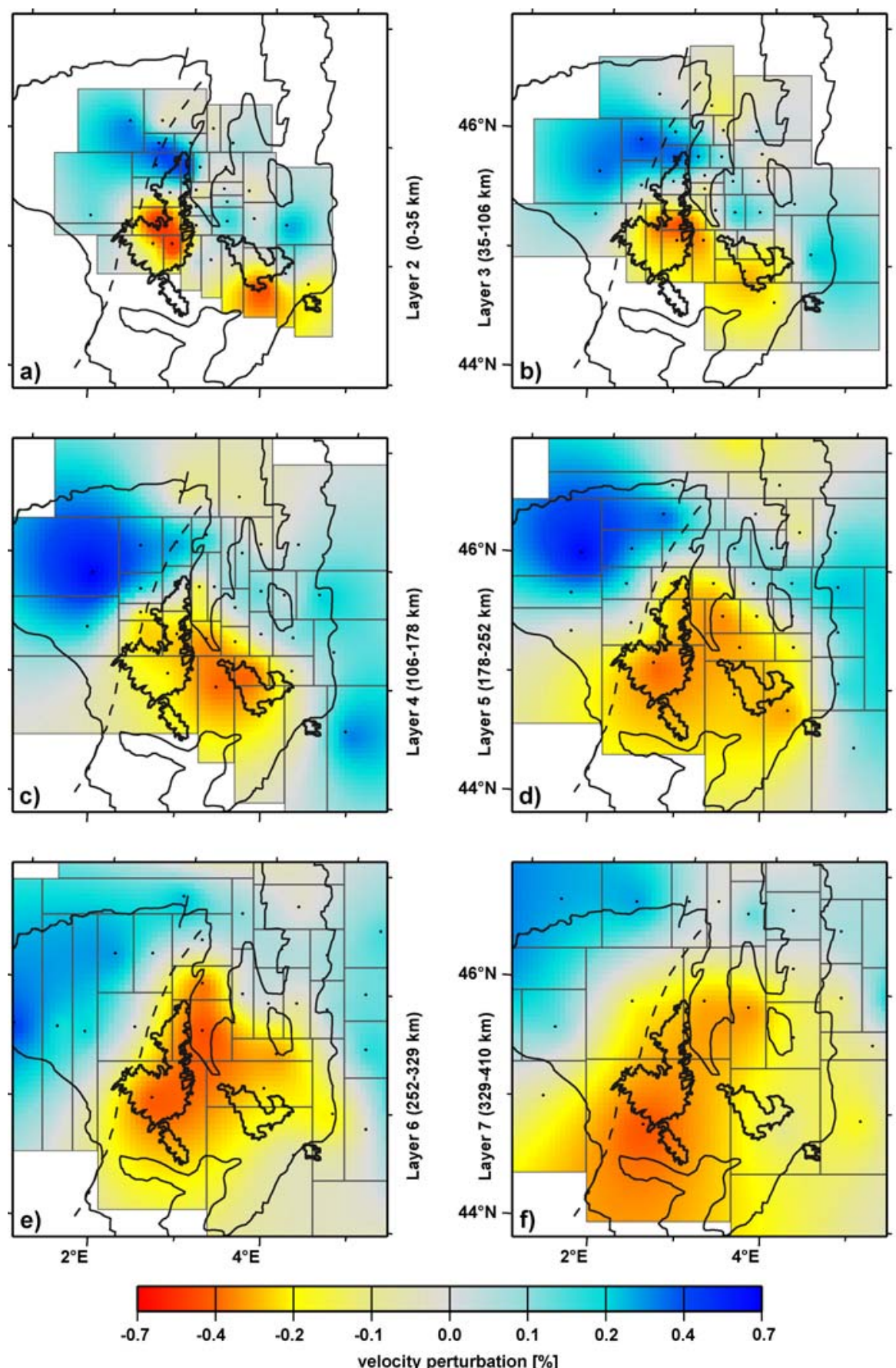
Fig. 10 (previous page $\&$ colour plate 5). Horizontal cross-section through the inversion model (layers 2-7). Shown are $P$-wave velocity perturbations with respect to the background model (compare Table 1). See Fig. 9 for the crustal density model
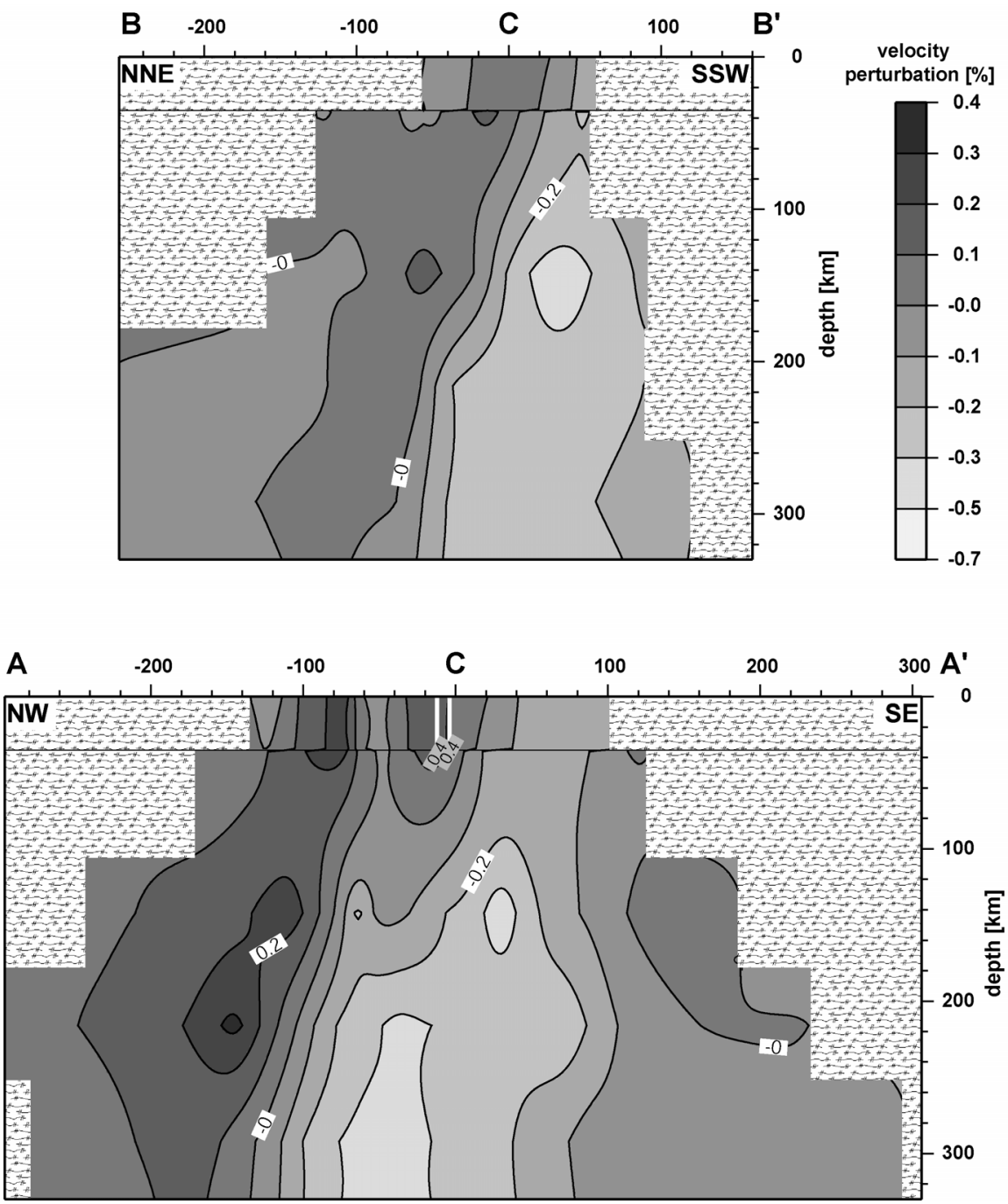

Fig. 11. Cross-section through the $P$-wave model after the final iteration, using the observed data. Section positions are indicated in Fig. 2. Distance is given in kilometres. Beside the velocity perturbation the position of the crustal density anomaly is displayed by two white contour lines ( $0.4 \%$ perturbation anomaly), just NW of the crossing point $(C)$ 
data input (Fig. 8). This high-density body coincides with a small highvelocity anomaly at the southern end of the Limagne Graben (Fig. 10a) that was already detected by Granet et al. (1995a, 1995b) and Gehrig (2004). The mantle LVA continues downwards into the deepest resolvable model layer (330 km depth, Fig. 10f and 11) and may even reach the $410 \mathrm{~km}$ discontinuity (top of the mantle transition zone), however a plume origin from the mantle transition zone cannot be fully resolved with our dataset.

\subsection{Resolution}

To test the reliability of velocity and density structures in the model resolution tests are performed. Additionally, the model resolution matrix $\boldsymbol{R}$ is analysed. Most main-diagonal elements of $\boldsymbol{R}$ are between 0.7 and 1 and the off-diagonal elements are quite small (generally well below 0.1 ), indicating a well-behaved inversion and not too much coupling (smearing) between the model parameters.

One reconstruction test (Fig. 12) shows the resolution of the vertical sections in Fig. 11. As input anomaly we choose a plume-like low-velocity anomaly (dashed lines in Fig. 12). To calculate a synthetic data set we use the same 3D ray geometry as for the real data and the same Bouguer gravity grid. The input model structure consists of a low-velocity zone reaching from beneath the Moho down to the base of the model at $410 \mathrm{~km}$ depth. The amplitude of the $P$-wave velocity contrast is $-1.2 \%$ within a $60 \mathrm{~km}$ radius and it decreases linearly to $0 \%$ at a radius of $110 \mathrm{~km}$. Accordingly a high-velocity zone combined with a high-density body is placed in the crustal layer. It has an inner radius of $20 \mathrm{~km}$ with a maximum velocity amplitude of $+1.4 \%$ (density $+1 \%$ ) and an outer radius of $35 \mathrm{~km}$.

After forward calculating synthetic travel time residuals and gravity data Gaussian noise (standard deviation: $0.1 \mathrm{~s}$ for the travel time residuals and $1 \mathrm{mGal}$ for the Bouguer data) is added. These noise amplitudes are similar to the uncertainties in the observed data.

The result of the iterative joint inversion using the synthetic dataset (Fig. 12) resolves the shape of the synthetic plume-like input structure especially in the deeper layers very well. The influence of the crustal highvelocity/high-density structure however bends the plume in the upper mantle layer three (35 km to $106 \mathrm{~km}$ depth, see Table 1) to the South. A smearing of the plume structure into the crustal layer could not be avoided. The average recovered velocity contrast is about $-0.9 \%$ (or $75 \%$ of the input anomaly). This demonstrates the problem of resolution of shallow structure and indicates an underestimation of recovered anomalies, what was 
also found in other studies (see also Keyser et al. 2002). The resolved density contrast is about $0.4 \%$ and it is slightly shifted compared to its original location. The perturbation amplitudes of velocity and density are underestimated. This is consistent with synthetic tests that reveal that JI-3D tends to underestimate velocity contrasts (Jordan 2003, Keyser et al. 2002).
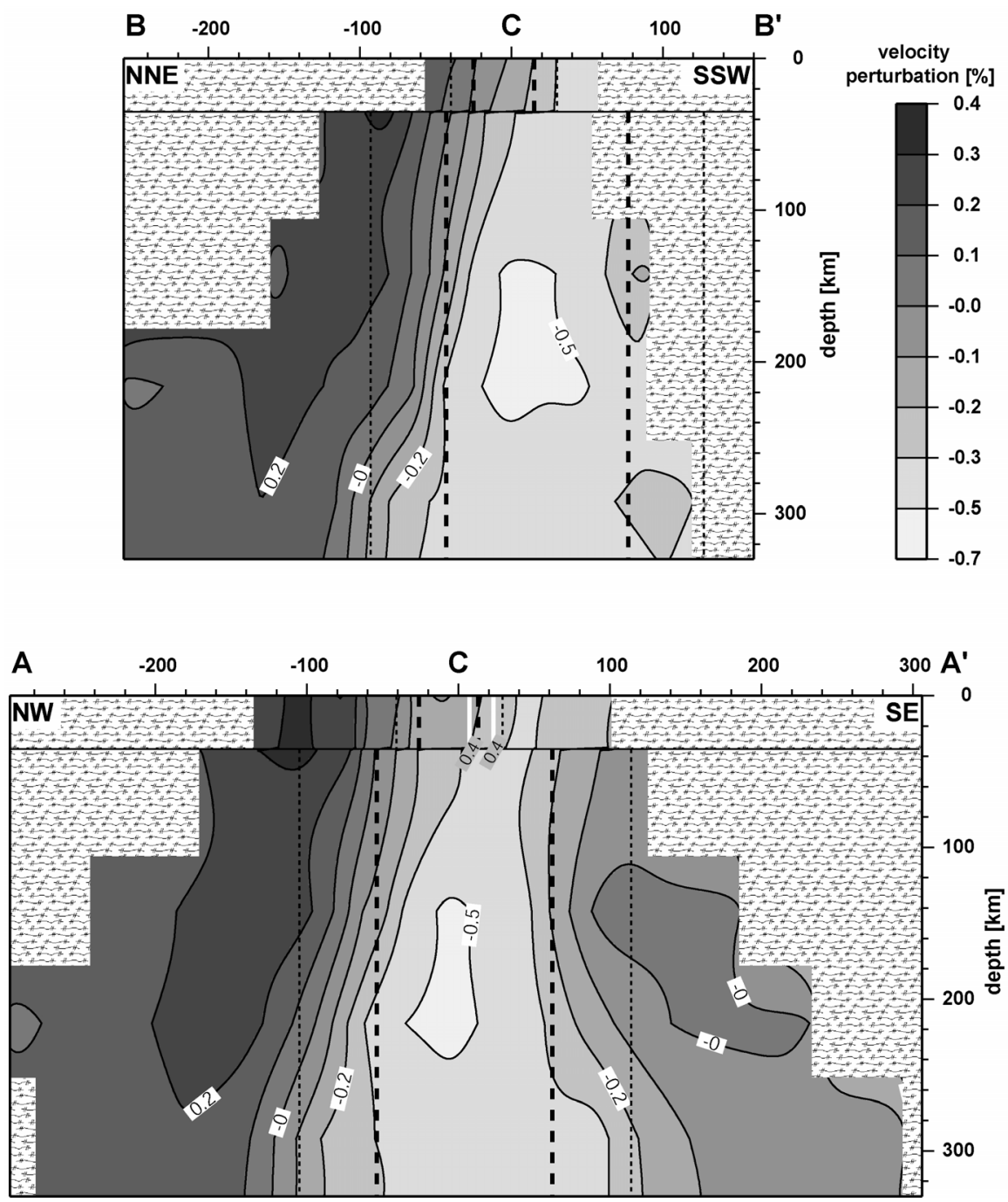

Fig. 12. According Fig. 11, but using synthetic data for a resolution test. The data is calculated using a cylindrical plume, with constant amplitude within the thick dashed lines, decreasing to $0 \%$ perturbation at the thin dashed lines. For details see text 


\section{Scattering at small-scale structures}

The teleseismic tomography in the Massif Central can resolve only structures larger than about $20 \mathrm{~km}$. However, small-scale heterogeneities $(<10 \mathrm{~km})$ in the lithosphere were detected by analysing the $P$-wave coda of teleseismic recordings (Ritter et al. 1997, 1998, Ritter and Rothert 2000, Hock et al. 2004). These studies are reviewed in the following. As data waveforms of 13 intermediate-depth events were selected (Fig. 13), which occurred mostly at more than $100 \mathrm{~km}$ depth (a complete list is given in Ritter and Rothert 2000). The recording stations were the mobile stations from the Massif Central 1991/92 project and seven stations of the permanent Auvergne network of the University of Clermont-Ferrand (Fig. 2).

Ritter et al. (1997) report about high frequency (2-4 Hz dominant frequency) scattered phases in the teleseismic coda, which are most probably generated at heterogeneities in the lower crust. Pronounced lower crustal heterogeneity was also discovered by Novak (1993) while studying the coda phases along two seismic refractions lines across the Limagne Graben. Both studies inferred that lower crustal heterogeneities of about 0.2$2 \mathrm{~km}$ diameter $(a)$ with velocity fluctuations $(\sigma)$ of a few percent could explain the observed scattered seismic phases. The teleseismic waveforms
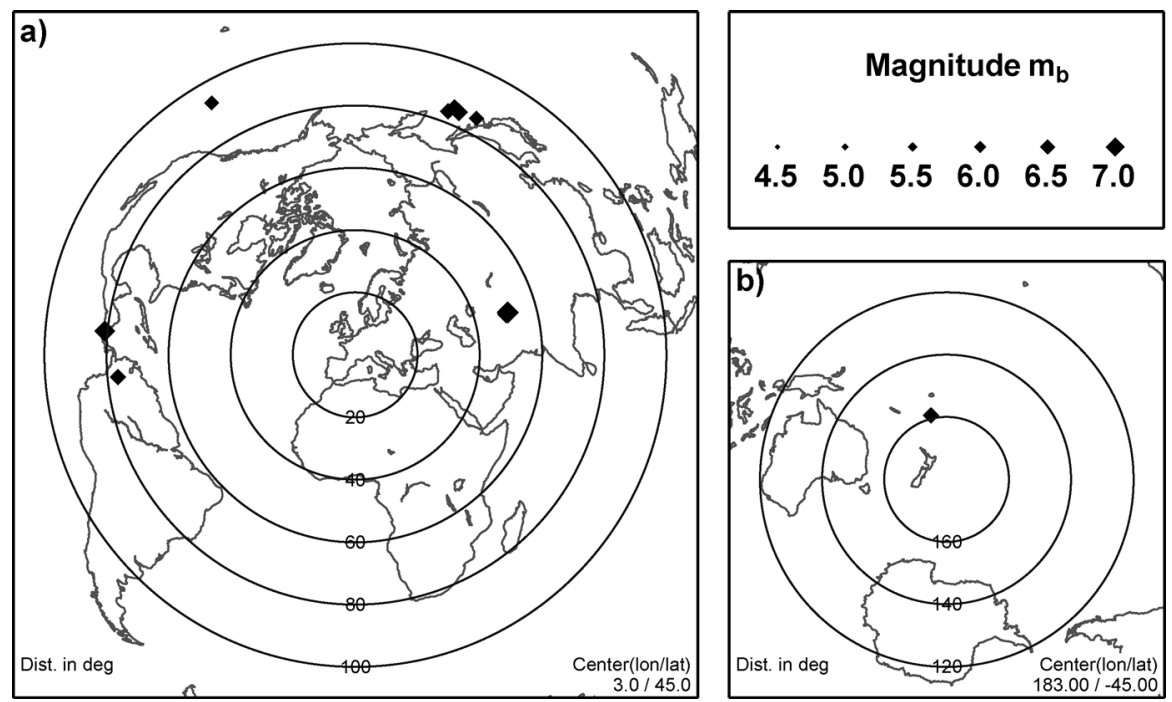

Fig. 13. Distribution of intermediate-depth earthquakes used for the scattering analysis of the $P$-wave coda. a) 12 epicentres with direct $P$-phases, b) one epicentre with first arrival $P K P$-phase 
were later studied with more sophisticated methods: For the teleseismic fluctuation wavefield method (TFWM) the scattered arrivals at a seismic station are separated from the mean (coherent) wavefield (Ritter et al. 1998). A data example is shown in Fig. 14 with STACK as mean wavefield and with residual seismograms (RES) containing the separated scattered phases of four stations. The ratio of the mean wavefield and the scattering intensities can be used to statistically describe the heterogeneity of the medium through which the wavefield propagated (for details see Ritter et al. 1998). As the TFWM cannot resolve the thickness of the scattering layer, only two optional models are given: scattering in the crust and in the whole lithosphere.

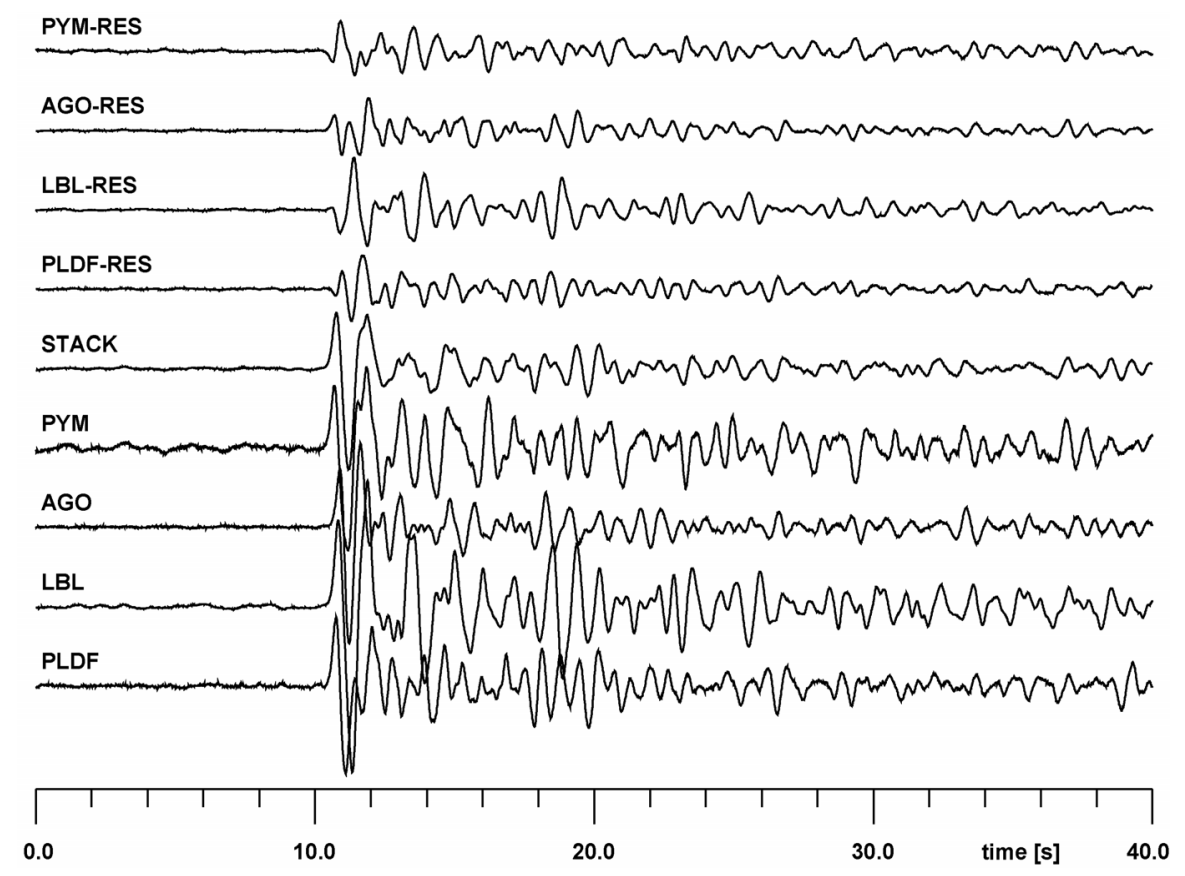

Fig. 14. Data example for the scattering analysis with the same amplitude scaling for all traces. The teleseismic waveforms were recorded by the permanent Auvergne network of the University of Clermont-Ferrand at the stations PLDF, LBL, AGO and PYM (lower four traces). The source is a $228 \mathrm{~km}$ deep Hindu Kush earthquake $(m b 6.0)$ on $21 \mathrm{st}$ March 1998. These recordings are stacked with the measured slowness $\left(7.9 \mathrm{~s} /{ }^{\circ}\right)$ and backazimuth $\left(73.6^{\circ}\right)$. Scattered signals are recovered by determination of residual seismograms at the individual stations (upper four traces) 
Ritter and Rothert (2000) used the events from Fig. 13 and determined a random medium with Gaussian or exponential distribution of the scatterers underneath the Massif Central with the following properties: If scattering occurs preferably in the crust, then $1 \mathrm{~km}<a<3 \mathrm{~km}$ with $4 \%<\sigma<10 \%$. Increased scattering in the lithospheric mantle would be compatible with $a>5 \mathrm{~km}$ and $\sigma \approx 1-3 \%$. The simulation of the teleseismic coda envelopes with the energy flux method after Korn (1997) gained a model with a 20$30 \mathrm{~km}$ thick scattering layer, which implies strong scattering preferentially in the crust. These heterogeneities are characterised by $1.5 \mathrm{~km}<a<5 \mathrm{~km}$ (strongly depending on the assumed correlation function, Gaussian or exponential) with $3.5 \%<\sigma<4.5 \%$ (Hock et al. 2004).

Compared to 11 other regions in Europe (e.g. Baltic Shield, North Germany, Frankonian Jura) the TFWM revealed that the most intense scattering occurs in the Eifel and Massif Central regions (Hock et al. 2004) which can be explained by magmatic intrusions related to the mantle plume activity (Ritter and Rothert 2000). Solidified gabbroic intrusions, for instance, in a mafic granulite lower crust have a $3-5 \%$ velocity contrast relative to the host rocks. Thus cooled magma chambers and dykes with dense cumulates in the lower and upper crust are regarded as strong seismic heterogeneities below the volcanic fields of the Massif Central.

\section{Discussion and Interpretation}

The applied joint inversion of seismic travel times and Bouguer gravity produces a stable result that can resolve a structure such as an upper mantle plume. Vertical smearing of the velocity structure affects partly crustal regions, but the mantle is well-resolved. The inversion result of a synthetic seismic low-velocity mantle plume (Fig. 12) shows a similar shape as the plume structure revealed by the observed data (Fig. 11). However, the amplitudes of $P$-wave velocity perturbations are underestimated. Likewise the density anomaly in the crustal layer (Fig. 9) is likely to be stronger than the modelled $+0.5 \%$ contrast.

The resolved upper mantle plume structure is estimated to have an average diameter of about $100-120 \mathrm{~km}$. The velocity contrast relative to the surrounding upper mantle ranges between $-0.5 \%$ and $-0.8 \%$ and the depth from about $35 \mathrm{~km}$ down to least $330 \mathrm{~km}$. The top of the upper mantle plume is not well resolved (within layer three, $35 \mathrm{~km}$ to $106 \mathrm{~km}$ depth, see Fig. 10b) and depends mainly on the parameterisation of the model grid. However, an asthenospheric upwelling to $60-80 \mathrm{~km}$ is assumed in the region (Werling and Altherr 1997). A forward calculation of near-vertical 
teleseismic rays through the low-velocity structure in Fig. 10 results in a maximum contrast of travel time residuals between the main anomaly and the surrounding region of about $0.3 \mathrm{~s}$ for a near vertical incidence. Compared to the maximum observed travel time residuals (see Sect. 2.2), this value confirms the underestimation of the velocity contrast as found by the synthetic modelling. Hence we assume a $P$-wave velocity $\left(v_{p}\right)$ reduction between $0.6 \%$ and $1.0 \%$ inside the plume that can better explain the observed contrast in relative residuals up to $0.4 \mathrm{~s}$. This velocity contrast corresponds to a temperature $(T)$ increase of $100-150^{\circ} \mathrm{C}$ using available $v_{p}-T$ relations which take into account inharmonic and inelastic effects in upper mantle material (e.g. Goes et al. 2004, Ritter 2005). For this temperature range and a diameter of $100 \mathrm{~km}$ the buoyancy flux of the Massif Central plume can be estimated to $0.09-0.2 \mathrm{Mg} / \mathrm{s}$ (Ritter 2005).

The Massif Central plume clearly reaches the bottom of our model (Fig. 10f and 11). This leads to the hypothesis for an even deeper source possibly in the mantle transition zone as determined for the Eifel plume (Ritter, this volume).

The Massif Central plume is situated below the southern part of the Limagne Graben and further to the South underneath the volcanic fields of Cantal/Monte Dore and Devès. At 35-106 km depth (Fig. 10b) the northern transition between low- and high-velocity perturbations is roughly along a line at $45.5^{\circ} \mathrm{N}$. This supports the hypothesis of an East-West striking lithospheric block boundary as suggested by Lenoir et al. (2000) based on geochemical analyses of mantle xenoliths. The western end $\left(\sim 2.5^{\circ} \mathrm{E}\right)$ of the LVA seems to be confined by a downward extension of the Sillon Houllier fault, which may act as another mechanical boundary for the asthenospheric upwelling. The change in fast directions of $S K S$-splitting observations also identifies the Sillon Houllier as a possible deep-reaching structural element (Granet et al. 1998).

The joint inversion of travel time and gravity data in the crustal layer results in a zone of increased velocity combined with a high-density body beneath the southern Limagne Graben. A crustal high-velocity zone was revealed in the region with crustal seismic tomography by Gehrig (2004). In the same region the scattering analysis (see Sect. 3) finds increased seismic scattering compared to other regions in Europe. We interpret these modelling results as cooled magmatic intrusions which remained in the crust while magma penetrated from the plume to the surface. These intrusions and the Cenozoic volcanic fields are thus the uppermost imprints of the Massif Central mantle plume. 


\section{Acknowledgements}

We thank M. Mai and C. Weidle for their critical and constructive remarks and J. Mathar for testing appropriate bandpass filters for the gravity data. The seismic waveforms were provided by the Massif Central project 1991/92 (Granet et al. 1995a), Geoscope (Paris) and RéNaSS (Strasbourg). Gravity data was provided by the Bureau de Recherches Géologique et Minière (BRGM, Orléans). Seismic processing was done using SeismicHandler (Stammler 1993). The figures were made using GMT (Wessel and Smith 1998).

\section{References}

Barth A (2002) P-Wellen-Tomographie des oberen Mantels und der Übergangszone unter Eifel und Zentralmassiv. Diploma thesis, Institute of Geophysics, University of Göttingen (in German)

Bauer C (1995) 3D Schweremodellierung krustaler Strukturen im französischen Zentralmassiv unter Einbeziehung seismischer und geologischer Informationen. Diploma thesis, Geophysical lnstitute, University of Karlsruhe (in German)

Birch F (1961) The velocity of compressional waves in rocks to 10 kilobars. J Geophys Res 66:2199-2224

Brousse R, Delibrias G, Labeyrie J, Rudel A (1969) Eléments de chronologie des eruptions de la Chaîne des Puys. Bull Soc géol France 8:223-245

Christensen NI, Mooney WD (1995) Seismic velocity structure and composition of the continental crust; a global view. J Geophys Res 100:9761-9788

Dèzes P, Schmid SM, Ziegler PA (2004) Evolution of the European Cenozoic Rift System: interaction of the Alpine and Pyrenean orogens with their foreland lithosphere. Tectonophysics 389:1-33

Downes H, Reichow MK, Mason PRD, Beard AD, Thirlwall MF (2003) Mantle domains in the lithosphere beneath the French Massif Central: trace element and isotopic evidence from mantle clinopyroxenes. Chem Geol 200:71-87, doi: 10.1016/S0009-2541(03)00126-8

Engdahl ER, van der Hilst R, Buland R (1998) Global teleseismic earthquake relocation with improved travel times and procedures for depth determination. Bull Seism Soc Am 88:722-743

Evans JR, Achauer U (1993) Teleseismic velocity tomography using the ACH method: theory and application to continental-scale studies. In: Iyer HM, Hirahara K (eds) Seismic Tomography: Theory and Practice. Chapman and Hall, London, pp 319-360

Hock S, Korn M, Ritter JRR, Rothert E (2004) Mapping random lithospheric heterogeneities in northern and central Europe. Geophys J Int 157:251-264, doi: 10.1111/j.1365-246X.2004.02191.X 
Gehrig M (2004) 3-D-Geschwindigkeitsstruktur der Oberkruste unter dem Limagne-Graben (Französisches Zentralmassiv). Diploma thesis, Geophysical Institute, University of Karlsruhe (in German)

Goes S, Cammarano F, Hansen U (2004) Synthetic seismic signal of thermal mantle plumes. Earth Planet Sci Lett 218:403-419

Granet M, Stoll G, Dorel J, Achauer U, Poupinet G, Fuchs K (1995a) Massif Central (France): new constraints on the geodynamical evolution from teleseismic tomography. Geophys J Int 121:33-48

Granet M, Wilson M, Achauer U (1995b) Imaging a mantle plume beneath the French Massif Central. Earth Planet Sci Lett 136:281-296

Granet M, Glahn A, Achauer U (1998) Anisotropic Measurements in the Rhinegraben Area and the French Massif Central: Geodynamic Implications. Pure appl geophys 151:333-364

Jordan M (2003) JI-3D - A new approach to high resolution regional seismic tomography: Theory and applications. PhD thesis, University of Göttingen

Kennett BLN, Engdahl ER (1991) Traveltimes for global earthquake location and phase identification. Geophys J Int 105:429-465

Keyser M, Ritter JRR, Jordan M (2002) 3D shear wave velocity structure of the Eifel plume, Germany. Earth Planet Sci Lett 203:59-82

Korn M (1993) Determination of site-dependent scattering Q from $P$-wave coda analysis with an energy-flux model. Geophys J Int 113:54-72

Korn M (1997) Modelling the teleseismic $P$ coda envelope: depth dependent scattering and deterministic structure. Phys Earth Planet Inter 104:23-36

Lenoir X, Garrido CJ, Bodinier J-L, and Dautria J-M (2000) Contrasting lithospheric mantle domains beneath the Massif Central (France) revealed by geochemistry of peridotite xenoliths. Earth Planet Sci Lett 181:359-375

Novak O (1993) Integrierte geophysikalisch-petrologische Interpretation des obersten Mantels und der unteren Kruste im Bereich des südlichen Limagnegrabens (Frankreich). Diploma thesis, Geophysical Institute, University of Karlsruhe (in German)

Martin M, Ritter JRR and the CALIXTO working group (2005) High-resolution teleseismic body wave tomography beneath SE-Romania - I.: Implications for three-dimensional versus one-dimensional crustal correction strategies with a new crustal velocity model, Geophys J Int 162:448-460

Matte P (1986) Tectonics and plate tectonics model for the Variscan belt of Europe. Tectonophysics 126:329-374

Miallier D, Michon L, Évin J, Pilleyre T, Sanzelle S, and Vernet G (2004) Volcans de la chaîne des Puys (Massif central, France) : point sur la chronologie Vasset-Kilian-Pariou-Chopine. C R Geoscience 336:1345-1353

Müller B, Wehrle V, Zeyen H, Fuchs K (1997) Short-scale variations of tectonic regimes in the western European stress province north of the Alps and Pyrenees. Tectonophysics 275:199-219

Piromallo C, Morelli A (2003) $P$ wave tomography of the mantle under the Alpine-Mediterranean area. J Geophys Res 108:2065, doi: 10.1029/ 2002JB001757 
Ritter JRR (2005) Small-scale mantle plumes: Imaging and geodynamic aspects. In: Wenzel F (ed) Perspectives in Modern Seismology, Lecture Notes in Earth Sciences 105. Springer Verlag, Heidelberg, 69-94

Ritter JRR The seismic signature of the Eifel plume. This volume

Ritter JRR, Rothert E (2000) Variations of the lithospheric seismic scattering strength below the Massif Central, France and the Frankonian Jura, SE Germany. Tectonophysics 328:297-305

Ritter JRR, Mai PM, Stoll G, Fuchs K (1997) Scattering of teleseismic waves in the lower crust: observations in the Massif Central, France. Phys Earth Planet Int 104:127-146

Ritter JRR, Shapiro SA, Schechinger B (1998) Scattering parameters in the lithosphere below the Massif Central, France, from teleseismic $P$-wavefield records. Geophys J Int 134:187-198

Ritter JRR, Mathar JP, Jordan M, Gabriel G Gravity anomalies and the Eifel plume in the western Rhenish Massif. This volume

Sobolev SV, Babeyko AY, Christensen U, Granet M (1997a) Temperature and dynamics of the upper mantle beneath the French Massif Central. In: Fuchs K (ed) Upper mantle heterogeneities from active and passive seismology. Kluwer Academic Publishers, Dodrecht Boston London, pp 269-275

Sobolev SV, Zeyen H, Granet M, Achauer U, Bauer C, Werling F, Altherr R, Fuchs K (1997b) Upper mantle temperatures and lithosphere-asthenosphere system beneath the French Massif Central constrained by seismic, gravity, petrologic and thermal observations. Tectonophysics 275:143-164

Stammler K (1993) SeismicHandler: programmable multichannel data handler for interactive and automatic processing of seismological analyses. Comp Geosci 19:135-140

Steck L, Prothero W (1991) A 3-D raytracer for teleseismic body-wave arrival times. Bull Seism Soc Am 81:1332-1339

Waldhauser F, Kissling E, Ansorge J, Mueller St (1998) Three-dimensional interface modelling with two-dimensional seismic data: the Alpine crust-mantle boundary. Geophys J Int 135:264-278

Werling F, Altherr R (1997) Thermal evolution of the lithosphere beneath the French Massif Central as deduced from geothermobarometry on mantle xenoliths. Tectonophysics 275:99-141

Wessel P, Smith WHF (1998) New, improved version of Generic Mapping Tools released. EOS Trans AGU 79:579 pp

Zeyen H, Achauer U (1997) Joint inversion of teleseismic delay times and gravity anomaly data for regional structures. In: Fuchs K (ed) Upper mantle heterogeneities from active and passive seismology. Kluwer Academic Publishers, Dodrecht Boston London, pp 155-169

Zeyen H, Novak O, Landes M, Prodehl C, Driad L, Hirn A (1997) Refractionseismic investigation of the northern Massif Central (France). In: Fuchs K, Altherr R, Müller B, Prodehl C (eds) Stress and stress release in the lithosphere. Tectonophysics, 275:99-117 